\title{
Welcome to Media Rhetoric-Where Human Persuasion and Technological Means Collide
}

\section{Samuel Mateus}

To cite this article: Samuel Mateus (2021) Welcome to Media Rhetoric-Where Human Persuasion and Technological Means Collide, Southern Communication Journal, 86:2, 165-174, DOI: 10.1080/1041794X.2021.1884282

To link to this article: https://doi.org/10.1080/1041794X.2021.1884282

\section{Published online: 03 Feb 2021.}

Submit your article to this journal $\sqsubset$

Џ Article views: 300

Q View related articles $\sqsubset$

View Crossmark data $ऍ$ 


\title{
Welcome to Media Rhetoric-Where Human Persuasion and Technological Means Collide
}

\author{
Samuel Mateus \\ Communication Studies, Madeira University, Funchal, Portugal
}

\begin{abstract}
The social world is made of rhetorical practices that constitute our sense of self. We are always using some kind of rhetoric exhorting others to understand our thoughts and influencing them to adopt new forms of doing and thinking. Central to persuasive communication today are Media. They not only help shape rhetoric, they are also a key means of disseminating rhetorical discourses. Media Rhetoric expression marks a fundamental stage of human communication and the development of civilization where Media became key rhetorical actors and social players. In this essay the scope of Media Rhetoric is briefly presented along with a discussion of two central fields of Media Rhetoric today advertising and digital rhetoric. By focusing on two case-studies - a print advertising campaign by Canadian Journalists for Free Expression (CJFE) and the QuitNow app - I demonstrate how persuasive strategies evolved in mediatized societies. Closing the article, some notes on Media Rhetoric from a Policymaking perspective are offered and reasons advanced to consider it, in the near future, as an important object of public attention.
\end{abstract}

\section{KEYWORDS}

Media; rhetoric; media

discourse; persuasion; digital media; advertising

Imagine a physical world of machines commanding us to use our spare time and directing us how to meet or how to work. Imagine, also, a symbolic world full of discourses swarming around. Everywhere we go we face them, no matter is it on the street, on work or on schools. And every time we are instructed, suggested, informed or even persuaded by them.

What if this those distinct and seemingly unrelated worlds would suddenly collide? What would it be if their independent paths would cross each-other? When a meteorite encounters our planet on its trajectory, we know it will alter the face of the Earth- for sure, it may be only an innocent crater, but huge transformations can go well beyond that. Is that the case when a symbolic word encounters a technological one? In this case, what changes could be involved in the crossing of human discourse and technological means of communication?

Well, hold on tight, that world has arrived already. Welcome to Media Rhetoric where the homo rhetoricus meets the Media.

We exhort, persuade and convince others through discourse. But now we exhort, persuade and convince others not just through verbal discourse but also through multimodal and multimedia forms of discourse including movies, pictures, sound, colors, size, design (Mateus, 2021b), memes, cartoons, or comic videos. Now, Rhetoric is facing a great challenge: to cope with a Media Society of multiple streams of discourse 24/7, 365 days a year. Discourse and persuasion had necessarily evolved. When symbolic and technological communicative worlds collide, we testify that Rhetoric progresses to a new level with all the transmutations in communication introduced by Media. Rhetoric - seen as persuasive communication- is present every time we communicate with each other. And when Media step 
into the rhetorical landscape we must prepare to significative changes in the ways people think, express, argument and get together.

We are entirely formed by rhetorical practices (Lanham, 1976) that constitute our social self. They help us shape our common world as well as constructing and negotiating between competing interpretations. As Burke (1969) suggests: we are always in some kind of rhetoric. But now we are also in a Media Rhetoric.

\section{Really, Media Rhetoric?}

Why one would want to put "Rhetoric" and "Media" in front of each other? For starters, the expression Media Rhetoric marks a fundamental stage of human communication and civilizational development where Media became key in Rhetoric. These are the reasons. On the one hand, Media Rhetoric alludes to the way Media integrated rhetorical practices in their daily routines and their ability to incorporate rhetorical discourses in their own contents. Media are powerful rhetorical dispositives opening a space where multiple social actors and institutions can disseminate their own discourses about the world. Media are paramount in today's dissemination of social discourses, amplifying, restricting or alter them while executing their daily routines. Media are the great stage of creation, transformation and diffusion of discourses, including rhetorical discourses.

Media Rhetoric, at this light, concerns all discourses- and above all persuasive ones- that are disseminated and given public visibility through Media. They are the technological means to most of contemporary rhetoric. In this sense, Media Rhetoric stands for a rhetoric that is acknowledged, accessed and performed in Media. Key examples of Media Rhetoric as mediated discourses came from the studies around Media Discourse (Lee, 2019), such, for example, racists speeches on media (Pohjonen, 2019). But more frequent examples of Media Rhetoric include studies around the rhetoric of political correctness in Media (Losey \& Kurthen, 1995), the rhetoric of news story structure (White, 2000) or the rhetorical functions of social media use (Wilkins et al., 2019).

On the other hand, Media Rhetoric expression consubstantiates another insight: media themselves as agents of rhetorical discourse. In this sense, Media Rhetoric assumes a perspective where Media are agents of persuasive discourse. They not only disseminate social discourses from individual and collective actors; by reporting discourses they are additionally subjects of discourse that can be examined from a persuasive standpoint. Media Rhetoric translates, thus, the influence of media functioning and operating under the influence of rhetoric mechanisms. Media practices make Media discursive agents capable of using, reusing, adapting and creating their own rhetoric elements in order to persuasively transmit their own, specific messages (they could be around commercial, economical, professional or social-cultural imperatives, for instance). Scholars are trying to isolate the exact elements of media discursive practices that originate from the rhetorical scaffolding. Investigations such as News Media's Rhetoric on Facebook (Yngve, 2019), or Rhetoric in Digital Communication: Merging Tradition with Modernity (Bendrat, 2019) are relevant examples of that.

Still, it is possible to discern a third meaning involved in such an expression as Media Rhetoric: the persuasive potential of Media (Mateus, 2021a). From this perspective, Media Rhetoric describes the incredible mingling between Rhetoric and Media. Fidalgo and Ferreira (2005), for example, pointed to the fundamental changes that Media encompassed by transforming Aristotle's rhetoric triangle (speaker, audience and message) to the modern rhetoric square (speaker, audience, message and Media). The modern rhetorical square developed under the aegis of mass media and it means Media are not another element but the key aspect of rhetoric today. Why? Fundamentally because Media caused the reformulation of every other elements of the rhetorical square.

Media Rhetoric means that the eloquence and classic rhetorical system has been translated into Media environments and it has been adapted to it along with the process of mediatization affecting sociocultural change (Hepp et al., 2015). Just as mediatization shapes and frames discourse and society, so the Media imprinted a series of transmutations to the rhetorical scaffolding that adapted persuasive communication to strongly mediatized societies. Therefore, one needs to reconsider the 
rhetorical tradition according to the changes introduced by Media in its canons, rhetorical proofs or even argumentation processes. One easy way to consider all the alterations entailed in Media Rhetoric is to recall that the canon of Delivery is now independent from the spatial-temporal bounds of the rhetor speaking to his audience. Media freed those limits introducing an expansion of the frequency, diffusion and reception of the messages as never seen before. And that autonomy for the Delivery canon meant new ways of communicating with audiences requiring new forms of employing the remaining canons such as Invention or Disposition.

Indeed, contemporary speakers must recognize the Delivery is affected by not just their verbal and non-verbal communication, but also by concomitant aspects of communication such as appearance, time of posting/publishing, media outlet, or even message's design and editing. Also, speakers must attend to the fact they may not have the time to fully pursue their lines of thought and must re-format them according to the media routines and operating rules. So, the speaker must rewrite her speeches consonant to the program she is in (television, social media, radio, etc). In either way, speakers rarely dispose of hours to convince their audiences and they must rely in rhetorical mechanisms to convey their messages effectively and efficiently using, for instance, metaphors (Porto \& Romano, 2013).

The fresh new perspective Media Rhetoric adds to the fields of Rhetoric, Media Discourse as well as Media and Communication studies has to do with its great potential to provide a rhetorical framework to register, describe, interpret and act upon mediated discourses as well as media discourses. In fact, Media Rhetoric seems especially adequate to offer an approach when we simultaneously consider Media as broadcasted discourse, Media as a type of discourse and Media as rhetorical devices of persuasive communication. This three-fold repartition between Media as mediating discourses, as entailing discourses and being a special kind of rhetoric, enable scholars to approach Media relevance as main catalysts of persuasion of new and existing ideas, values, causes and lifestyles.

\section{Where can I find Media Rhetoric?}

Media Rhetoric is everywhere, from television or print advertisements and social media's memes, to smartphone apps. Because Media are intrinsic to mass-communication and every day, personal and professional communication, Media Rhetoric can study a panoply of objects: media discourses, media discursive operations or even the media-influenced transformation of Rhetoric. More clearly, it may research social media's verbal and visual discourses, videogames, newspaper articles, or describe how Media (for example, a software) can function as central persuasive agents. In the remainder of this essay, I focus on two dimensions of today's Media Rhetoric research: advertising and digital rhetoric. In particular, I demonstrate how Media Rhetoric has been developing as a domain of study of persuasive communication by focusing in two cases-studies. In each case, we assist to the radical influence of rhetorical technique on Media, as well as Media's ultimate impact on contemporary Rhetoric. I conclude with commentary on the potential effects our understanding of Media Rhetoric might have on policy making in Europe.

\section{Advertising as Media Rhetoric}

Advertising deserves a special place since it is persuasive, pervasive and ubiquitous. Given we are constantly assaulted by thousands of persuasive messages each day, Advertising offers a great case to explain the importance and functioning of Media Rhetoric.

Digital rhetoric contemplates many forms of persuasive communication from political and ideological messages rendered visible in online forum or social media's posts, to apps and software tailored to make its users to perform certain given tasks.

A major part of rhetorical studies on advertising come from Marketing Management and Consumer Psychology scholars since advertising intends to persuade consumers, this is, to modify 
the way they think or act toward a given product or service. It communicates by convincing people through an array of multimodal messages and persuasive appeals.

Both the practices of rhetoric and advertising present similar veins: they are tasked with decisions about the benefits to the audience, target messaging or the discursive construction of attributes. Either rhetor or advertiser, the task is to identify and to differentiate the available means of persuasion- the very core definition given by Aristotle in his Rhetoric.

Different audiences and persuasive situations require different stratagems and adaptations if the desired outcome is to be achieved. Advertising rhetoric is audience/customer-centered and focused on the different moods, hopes and fears they need to address in order to locate their messages in a persuasive framework. So, rhetoric and advertisement are always a co-creation: while the rhetor/ advertiser attends to the needs of his audience, she allows the audience to act, think, believe or feel while judging the communicative message.

The Information is ammunition advertising campaign of Canadian Journalists for Free Expression (CJFE) (Figure 1) consubstantiates a great case where rhetoric and mass communication join forces to create a unique thought-proposition in which free speech and press liberty are advocated. This is an example of Media Rhetoric: while rhetoric gives the contours of the persuasive communication by using a metaphor, the constraints related to the printed media instructed this metaphor are given pictorially. Both Media and Rhetoric are intrinsically related, and the message impact derives directly from this association.

\section{How does this print advertising rhetorically perform?}

It is made convincing because it has in account the media constrains of print advertising: it condenses its strong message in both a verbal and pictorial metaphor. The verbal metaphor - Information is ammunition - is also a rhyme making it easier for consumers to recall. It is a very small slogan that yet projects itself with great consequences about the importance of free journalism in a democracy. The pictorial metaphor comes from the image presented: it consists in a pictorial form similar to a gun composed by different objects involved in the reporting of news such as a tripod, an audio recorder or SD cards. The elements represent information and the pictorial composition of these elements alludes to a gun. So, the pictorial metaphor reinforces the verbal metaphor. It forms a Contextual metaphor (MP1) where one term is depicted and the other is not depicted but unambiguously suggested by the pictorial context (Forceville, 1996). It is also a metaphor in absentia where the target term is explicitly absent, even if alluded to.

Just as I am avoiding a full rhetorical analysis to the CJFE advertisement, I cannot refrain from stating the total metaphor engaged in this humble but rhetorically pregnant example. By means of a metonymy, journalism is here referred by the name of information offering us a compelling and suggestive statement: the free-speech imperative to a strong journalism is conceived as a war. And journalism can be a powerful gun in the war to fight misinformation, ignorance and propaganda.

This tough assertion is presented in an assertive and condensed form where citizens can apprehend it in a matter of seconds by just catching the verbal and pictorial metaphors. Part of its persuasive appeal comes from the way it changes the common opinion (doxa) by comparing journalism to a war and information to the ammunition necessary to win it. The metaphor used in this case is captivating and it can change citizens minds about the significance of journalism in modern societies. Tailored in a simple message (one sentence, one picture), this advertising becomes persuasive by working with a metaphor capable of put journalism into a fresh, new and convincing perspective. Just like a bullet can change people's life, so information is here contended with such a power. This makes journalists a kind of guerrilla fighters where their (metonymical) pen is, indeed, mightier than a (metonymical) sword.

In this example, rhetoric is not achieved in completely and absolute verbal terms. Instead of relying in dense, argumentative or lengthy speeches, the ad speaks volumes by the strong metaphor it employs. This is the power of Media Rhetoric: it deploys rhetoric mechanisms the new context of 


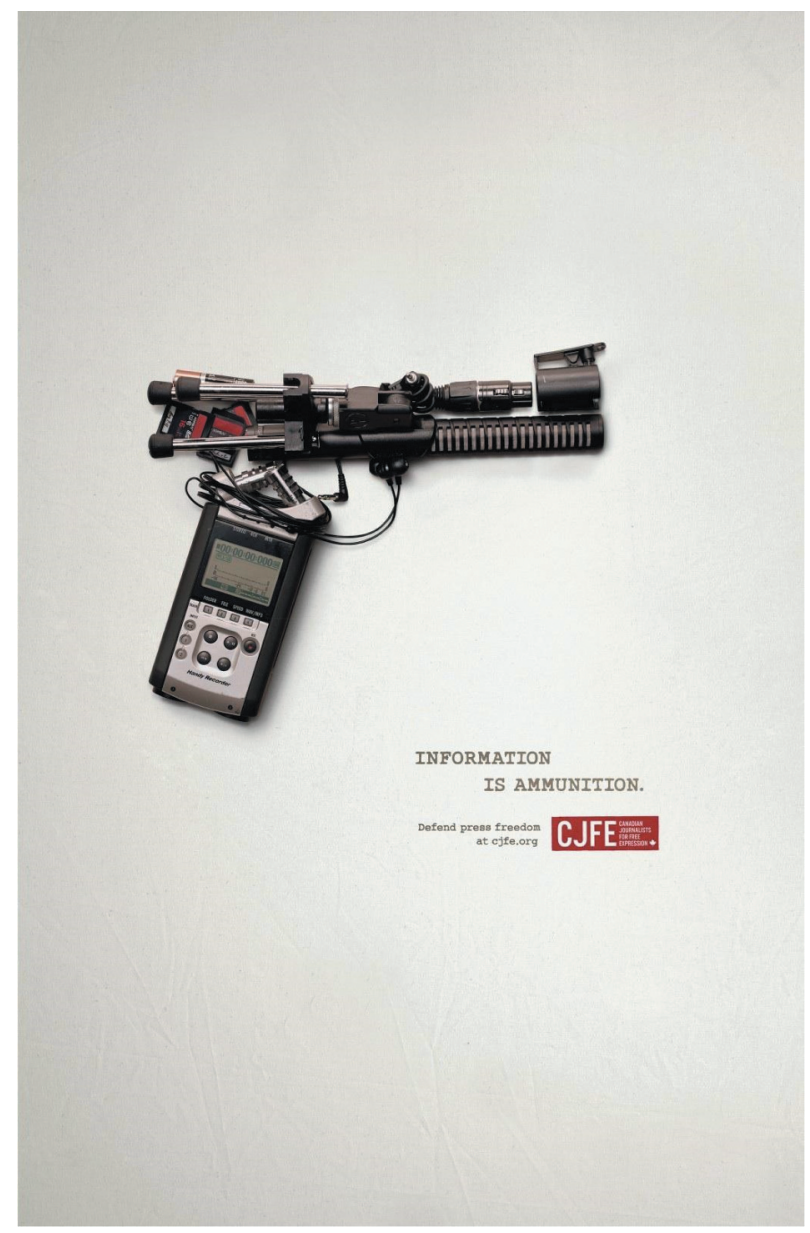

Figure 1. Example of the information is ammunition CJFE advertising campaign. Advertiser: CJFE, the Canadian Journalists for Free Expression (July, 2014)Agency: Juniper Park, Toronto, CanadaSource:Ads of the Worldhttps://www.adsoftheworld.com/media/print/ canadian_journalists_for_free_expression_defend_press_freedom_1.

modern Media as a strategy to adapt to their attributes. Television commercials can vary between 15 and 60 seconds. Print advertisements may even have a smaller fraction of time to be apprehended as readers and internet users are mostly focused in certain tasks when they came across the advertising persuasive messages. Pictorial metaphors can be seen as an answer to this need of conveying specific (persuasive) messages quickly in media environments where attention span is significatively reduced.

The Information is ammunition advertising campaign of Canadian Journalists for Free Expression (CJFE) is, therefore, an interesting case-study of Media Rhetoric in contemporary times that exemplifies the employment of Rhetoric in Media crafting its message according to the pictorial potential of print Media and its reduced attention-span.

\section{The digital in Media Rhetoric}

Digital Rhetorical is an encompassing expression to refer to the digital rhetorical practices. At this light, it can function as an important tool to recognize how social discourse inhabits and is reproduced in online environments. This is close to the sense Richard Lanham (1993) originally used the expression "digital rhetoric" as an emerging academic discipline centered on digital media and in the new digital genre of discourses. Digital rhetoric here focuses on the role of rhetoric on the 
formation of online communities and social identities and the role of new media in the exacerbation of collective discourses. This nethoric is sometimes referred as cyber-rhetoric (Albaladejo, 2014) seen as digital discourse's rhetoric.

A scholarly but essentially empirical approach to Digital Rhetoric is given through studies that see New Media as producers of persuasive discourses. For example, Fogg (2003) suggested the use of the word Captology to envision digital technologies as persuasion Media. Captology is the partial acronym of Computers as Persuasive Technology and basically claims a perspective in which computers are particularly useful in persuading people for the purpose of changing people's attitudes or behaviors such as buy certain products, or hand over personal information. It explores the intersection between persuasion in general (influence, motivation, behavior change, etc.) and computing technology, including design, research, and program analysis of interactive computing products (such as the Web, desktop software, specialized devices, etc.) as its objects of study.

I want now to concentrate on the persuasion levels entailed in digital technologies as an illustration of Media Rhetoric in computers and digital environments. Together, they demonstrate how computers are today key persuasive agents capable of change what we think and do. As Captology argues (Fogg, 2003), one can see computers at a macro or at a micro level of persuasion.

Microsuasion designates the persuasive intents assimilated in certain components, elements or features of a digital product or service (i.e, software). Urging users to give feedback by filling a form is an example of this microsuasion attribute of digital technologies. It concerns the interface and stimulates users to interact with the computer. It is based on converting a given disposition into a tangible and perceptible action.

On the other hand, macrosuasion designates an overall digital product or computer software designed, from the start, to be persuasive. It concentrates on a computer product to be presented as a persuasive mechanism to alter dispositions, attitudes or behaviors. Its sole purpose and main intent are to instill behavioral changes. Baby think it over, QuitSmoking or Quitnow (Figure 2) are just three of the dozens of digital apps that are intended to produce outcomes in its users.

Quitnow app is presented as the most complete tool to stop smoking. By offering real-time statistics (how many days since the last cigar, the money saved, or the time won back) along with other functionalities, the app intends to be the ultimate technological persuader. It exemplifies a macrosuasion approach to Digital Rhetoric since the whole purpose of Quitnow is to help users quitting smoking. Remark how rhetoric is adapted or re-shaped into digital environments with macro persuasion. Instead of relying on speech, the app offers a digital interface (based in the smartphone) to the user himself. The app acts persuasively because it can motivate the user to stay healthy and follow his resolution. But also because it is addressed to a highly motivated individual. By inserting him in a community of fellow ex-smokers, it even adds identification to the audience.

Another aspect involved in Quitnow- as with many other similar apps- is to gamify a difficult life decision: quit smoking. The Achievements section reinforce the personal motivations assuring users to

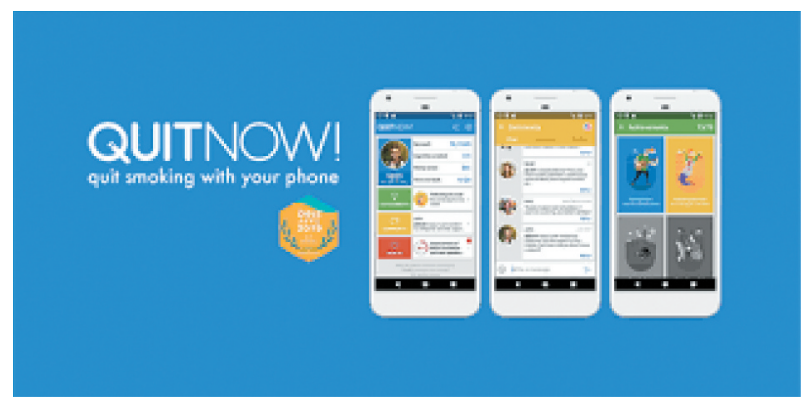

Figure 2. QuitNow, a macrosuasion example. We use this picture under the Fair Use legal doctrine under which the unlicensed use of copyright-protected works in scholarship and research circumstances are allowed. Please see Section 107 of the US Copyright Act. It can be found at https://www.facebook.com/QuitNowApp/. 
accomplish small daily tasks that keep them on track. The overall objective of quit smoking is, therefore, accomplished by earning successful achievements: these are the little steps that keep users motivated.

A focus on the rhetorical canon of Logos can also be discerned in the preoccupation of giving health tips and information based on World Health Organization guidelines. But it is Pathos the rhetorical canon most alluded in this app. By continuously stressing the emotional feeling of success, Quitnow persuades because it arises positive feelings and self-esteem in the content of its messages, as well as in its different app sections- as Community for example (Figure 3). Captology as an empirical approach to Digital Rhetoric emphasizes human-computer interaction as a type of relationship that can be based on persuasive intent. It makes computers persuasive agents stealing human from the exclusivity of persuasion. Despite that, computers can only act as macro persuaders as long as there are human motivated to use them as such. One of the most important teachings it gives us has to do with the expansion of the persuasion field into technology. It shows us that speeches are important elements of Digital Rhetoric but not the only ones. Computers, software and apps assume also a persuasive task, whether at a micro or a macrolevel.

\section{Closing thoughts: Media Rhetoric and policymaking}

Persuasive mass-mediated communication is not new. Yet, the exponential growth of personal and social media as well as the ubiquitous presence of Media in our life certainly calls for the measuring of the impact that Media and digital technologies cause to human communication and how we socialize,

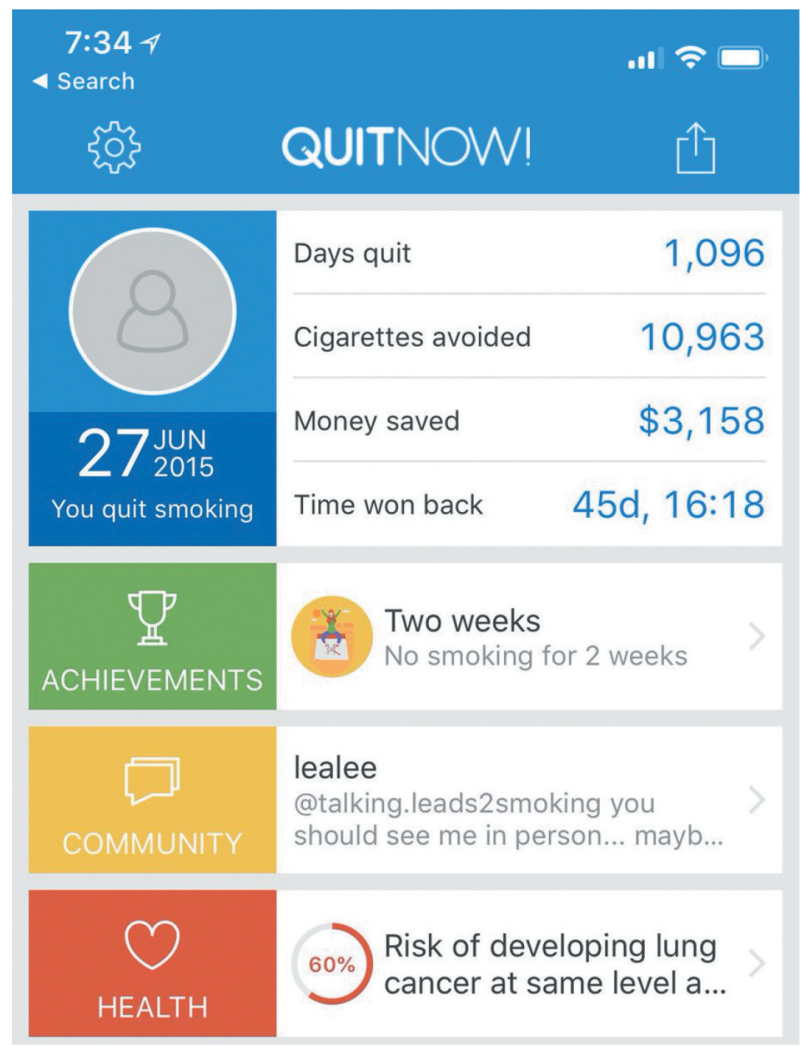

Figure 3. Quitnow homescreen. We use this picture under the Fair Use legal doctrine under which the unlicensed use of copyrightprotected works in scholarship and research circumstances are allowed. Please see Section 107 of the US Copyright Act. It can be found at https://www.facebook.com/QuitNowApp/. 
work and, of course, persuade. Media Rhetoric is now starting to emerge in Europe getting advantage of the previous approaches already taken in North America such as rhetoric advertising studies (McQuarrie \& Phillips, 2008), Captology (Fogg, 2003) or procedural rhetoric in videogames (Bogost, 2007). As these approaches tend to consolidate in scientific literature, more and more researches will be undertaken to clarify what is the scope of Media Rhetoric, how it has appropriated classical rhetorical tradition and, above all, its consequences on human and technological communication.

There are a number of conditions to fulfill in order for societies better discern their implications. But probably one of the most critical is that an interdisciplinary approach is required. Scholars from communication, rhetoric, advertising, marketing, human-computer interaction and media studies must converge in order to build an in-depth appraisal of the extent of Media Rhetoric and the meaning of the crossing between humanist rhetoric and technological Media. Those studies would provide us with meticulous analysis and measurable, objective, and, in some cases, replicable results. They will encourage the development of qualitative and quantitative methodologies trying to predict and enhance its outcomes.

From a policymaking standpoint, a better knowledge of today's Media Rhetoric is not just a stimulant academic endeavor but also a pressing social need. Here are some reasons European and World governments (as well private institutions) should develop a think tank on Media Rhetoric.

First of all, Media are pervasive and omnipresent. This means some of us pass more time interacting with communication technologies than in interpersonal, presential intercourse. Following the firstquarter 2018 Nielsen Total Audience Report, American adults spend over 11 hours per day listening to, watching, reading or generally interacting with media. This is almost the entire period we are awake. Radio reaches $92 \%$ of adults on a weekly basis; live and time-shifted TV has a weekly reach of $88 \%$. According to research from RescueTime, an apps for iOS and Android created to monitor phone use, people spend an average of 3 hours and 15 minutes on their phones every day. Almost $60 \%$ of the world's population is already online, and the GlobalWebIndex 2020 suggest that more than half of the world's total population will use social media by the middle of this year. In fact, according to Digital 2020 report (Figure 4), there were worldwide 3.80 billion social media users in January 2020, with this number increased by more than 9\% (321 million new users) since last year. Globally, more than 5.19 billion people now use mobile phones, with user numbers up by 124 million (2.4\%) over the past year.

Policymakers should be attentive to these statistics as they have huge implications in the way people socialize, debate, and decide. Moreover, Media fulfill vital role in culture by entertaining and providing

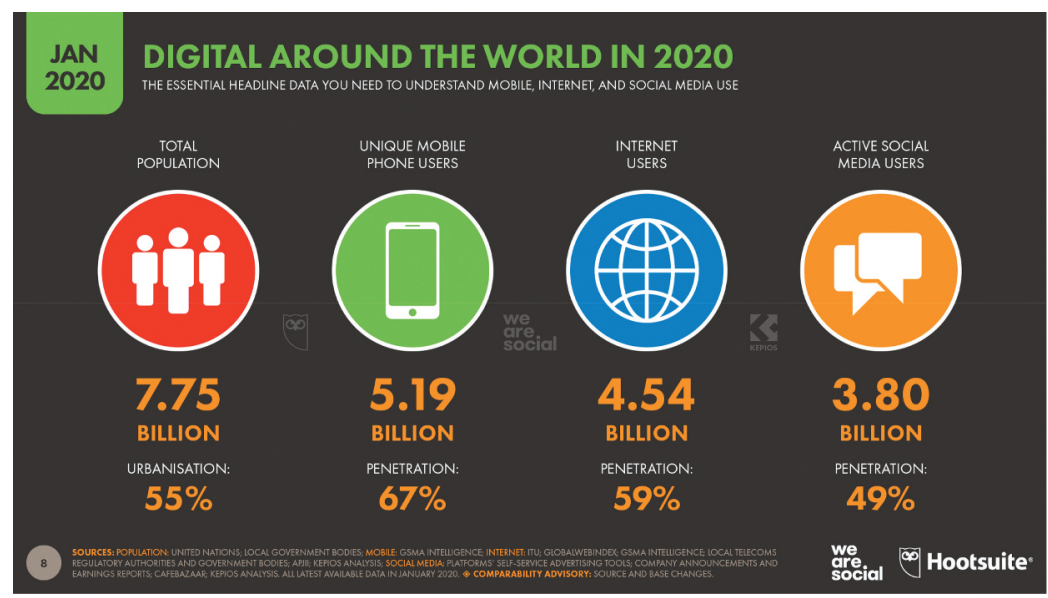

Figure 4. Digital 2020 report. Copyright belongs to Hootsuite at https://wearesocial.com/blog/2020/01/digital-2020-3-8-billionpeople-use-social-media. 
an outlet for imagination and social imaginaries; by providing the fundamental means to education and information; by serving as a public forum for discussion-including a rhetorical definition of the issues at hand (Lule, 2013); and acting as a watch and ultimate line of defense of citizens in questions of corruption, abuse of power, political or gender violence among many other subjects of public scrutiny. Given the massive exposure to Media, it is of critical importance to assess the persuasive dimension related to Media, whether they assume themselves as platforms that remediate existing discourses, whether they assume themselves as having a specific persuasive impact on the creation of Media and social discourses.

Second, the Media Rhetoric consequences on Education are of paramount importance. GlobalWebIndex 2018- involving the analysis of 31 countries- concluded that people between 16 and 24 years spend, in average 3 hours per day on social media. Besides, like procedural rhetoric alert us, videogames contain in themselves specific procedures that have a rhetorical nature of convincing players about the nature of a world. They make strong claims about how the world works by the processes they embody. In his book, Persuasive Games: The Expressive Power of Videogames, Bogost (2007) argues that games craft laws and rules within a game to convey a particular ideology. He gives the example of the first-person shooter America's Army, and contends that the game "serves as a convincing procedural rhetoric for the chain of command, the principle structure new recruits must understand immediately" (Bogost, 2007, p. 130). According to him, the videogame highlights government (mainstream) values and authority, suggesting to players, by the actions and procedures it enacts, that they should uncritically accept the missions they are provided.

If young children pass several hours a day playing these rhetorical procedures in videogames, it must be likewise recognized the implications that Media Rhetoric can potentially have in modeling the mental and symbolic structures of young people about the social world. Understanding the risk of encapsulating certain procedures in videogames that may convince players about a given ideology or political perspective must, no doubt about it, be considered by future policymaking.

Third, and in relation to what has been claimed before, studying Media Rhetoric should concern policymakers because the collision of Rhetoric and Media means potential new forms of transmitting, sharing and disseminating hegemonic discourses. In a time where everyone with Internet can reach a public status and publish everything he finds appropriate, it is much easier to massify, standardize and stereotype discourses. More, it even be easier to render them hegemonic by the use of nonconventional messages (such as memes or the use of images, video and social media channels) and the utilization of mainstream media.

The way Media convince us- through discourses they propel or through action they incentive us to do- must be carefully examined. Just like a given market needs public supervision by institutional instances, so the Media use of persuasion and the persuasive discourse disseminated through Media would benefit from a public supervision capable of preventing abuses of rhetorical discourse and persuasive practices intended to vilify institutions, personalities and collective values.

These are just a few notes on the public importance of Media Rhetoric. How we express ourselves is as much important as the content we vent. Media Rhetoric alert us to the manifold ways of conveying claims, arguments and perspectives about the social world without necessarily use words. Be it through pictorial metaphors, be it through videogames and apps, the world we live in is much complex from a persuasion perspective.

Understanding the combined effect of both Media and Rhetoric is, then, crucial, to comprehend our own time. Policymaking, in this respect, has the tremendous responsibility of not ignoring Media discourses and rhetoric and the way they convince us to adopt new attitudes. The effect of Media Rhetoric is not inescapable but certainly deserves our best attention since it can influence, model and impact how we think and collectively act in the world. 


\section{Disclosure statement}

No potential conflict of interest was reported by the author.

\section{References}

Albaladejo, T. (2014). Rhetoric and discourse analysis. In I. Olza, O. Loureda, \& M. Casado-Velarde (Eds.), Linguistic insights: Language use in the public sphere: Methodological perspective and empirical applications (pp. 19-51). Peter Lang.

Bendrat, A. (2019). Rhetoric in digital communication: Merging tradition with modernity. Res Rhetorica, 6. 111-124. https://doi.org/10.29107/rr2019.3.8

Bogost, I. (2007). Persuasive games: The expressive power of videogames. The MIT Press. https://doi.org/10.7551/ mitpress/5334.001.0001

Burke, K. (1969). A rhetoric of motives. University of California Press.

Fidalgo, A., \& Ferreira, I. (2005). Retórica Mediatizada. Revista de Comunicação e Linguagens, 36, 151-156. Relógio d'Água

Fogg, B. J. (2003). Persuasive technology. Using Computers to change what we think and do. Elsevier. https://doi.org/10. 1016/B978-1-55860-643-2.X5000-8

Forceville, C. (1996). Pictorial metaphor in advertising. Routledge.

Hepp, A., Hajarvard, S., \& Lundby, K. (2015). Mediatization: Theorizing the interplay between media, culture and society. Media, Culture \& Society, 37(2), 314-324. https://doi.org/10.1177/0163443715573835

Lanham, R. (1976). The motives of eloquence: Literary rhetoric in the renaissance. Yale University Press.

Lanham, R. (1993). The electronic word: Democracy, technology, and the arts. University of Chicago Press.

Lee, H.-J. (2019). Analysis of media discourse on fairness of education. Asian Journal of Education, 20 (3), 853-882. https://doi.org/10.15753/aje.2019.09.20.3.853

Losey, K., \& Kurthen, H. N. (1995). "The rhetoric of "political correctness" in the U.S". Media. Amerikastudien, 40 (2), 227-245. https://www.gvsu.edu/cms4/asset/2EF13597-D42F-119E-4BC17F1486F70448/losey_kurthen_-_the_rhetoric_of_political_correctness_in_the_u.s._media_1995.pdf

Lule, J. (2013). Understanding media and culture. Flat World Knowledge.

Mateus, S. (Ed.). (2021a). Media Rhetoric: How advertising and digital media influence us. Cambridge Scholars Publishing.

Mateus, S. (2021b). When Homo Rhetoricus meets the Media - the field and scope of Media Rhetoric. In S. Mateus (Ed.), Media Rhetoric: How advertising and digital media influence us. Cambridge Scholars. (Forthcoming).

McQuarrie, E. F., \& Phillips, B. J. (Ed.). (2008). Go figure!: New directions in advertising rhetoric. M.E. Sharpe.

Pohjonen, M. (2019). A comparative approach to social media extreme speech: Online hate speech as media commentary. International Journal of Communication, 13 (19), 3088-3103. https://doi.org/1932-8036/20190005

Porto, D., \& Romano, M. (2013). Newspaper metaphors: Reusing metaphors across media genres. Metaphor and Symbol, 28(1), 60-73. https://doi.org/10.1080/10926488.2013.744572.

White, P. R. R. (2000). Media objectivity and the rhetoric of news story structure. In E. Ventola (Ed.), Discourse and community. Doing functional linguistics, language in performance (Vol. 21, pp. 379-397). Gunter Narr Verlag.

Wilkins, D. J., Livingstone, A. G., \& Levine, M. (2019). Whose tweets? The rhetorical functions of social media use in developing the Black Lives Matter movement. British Journal of Social Psychology, 58(4), 786-805. https://doi.org/10. $1111 /$ bjso. 12318 .

Yngve, B. H. (2019). News Media's Rhetoric on Facebook. Journalism Practice, 13(7), 853-872. https://doi.org/10.1080/ 17512786.2019.1577163. 